CANCER

\section{Platelets signal cells to invade}

Platelets, the wound-patching warriors of the bloodstream, also have a more sinister role: priming cancer cells for metastasis, the establishment of tumours in parts of the body distant from the original site.

Richard Hynes and his colleagues at the Massachusetts Institute of Technology in Cambridge injected mice with colon- and breast-cancer cells that had been incubated with platelets. Fourteen days later, the mice displayed many more metastases in their lungs than did mice injected with cells not incubated with platelets.

Platelets secrete a signalling protein called TGF- $\beta$, which acts on the cancer cells. Direct contact between platelets and cancer cells activates a protein, NFkB, in the cells. Both events make these cells more invasive. Deleting TGF- $\beta$ solely in platelets or inhibiting NFKB in the tumour cells suppressed the lung metastases.

Cancer Cell 20, 576-590 (2011)

\section{CLIMATE CHANGE}

\section{Out-of-reach goal to limit warming}

Even if the world makes longterm cuts to carbon emissions of $90 \%$ relative to 2009 levels, it will miss the target of limiting global warming to $2^{\circ} \mathrm{C}$ by the end of the millennium.

Only if larger cuts are made both long term and globally, starting in the next couple of decades - at an annual rate of at least $3 \%$ could that target be met.

Pierre Friedlingstein at the University of Exeter, UK, and his colleagues used a coupled climate-carbon-cycle model

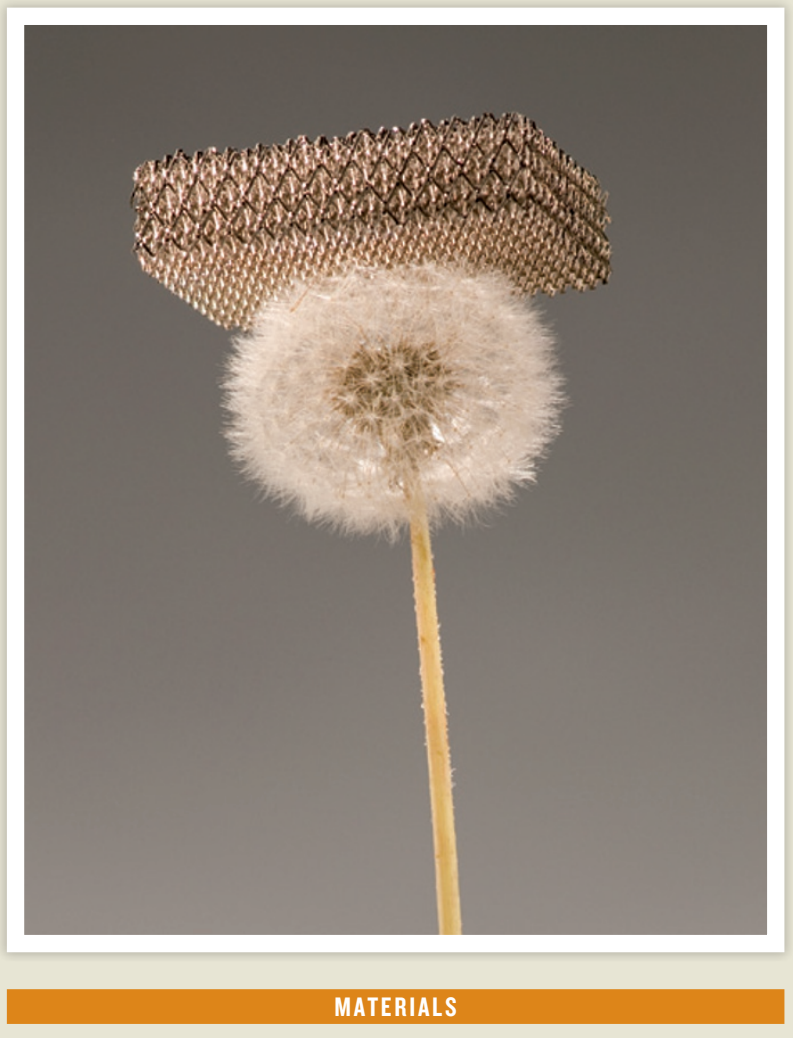

\title{
Light, springy mesh
}

Researchers have created a metallic microlattice that has a density less than that of air and can spring back into shape after being compressed by more than $50 \%$.

Low-density materials such as foams usually have inferior mechanical properties, including low strength. Tobias Schaedler at HRL Laboratories in Malibu, California, and his colleagues fabricated a three-dimensional polymer lattice, and coated it with a thin nickel-phosphorus film. They then etched away the polymer, leaving an ultralight lattice of hollow tubes (pictured) with a density of just 0.9 milligrams per cubic centimetre. The microlattice had better mechanical properties than other lightweight materials and was able to absorb and dissipate energy at a level similar to viscoelastic polymers.

The authors attribute these properties to the material's ordered lattice structure, and say that such microlattices could be useful as battery electrodes or sound or vibration dampers. Science 334, 962-965 (2011)

to simulate global warming until the year 3000 in various scenarios. If a $3 \%$ yearly reduction rate began 30 years from now for a total emissions cut of $90 \%$, the average global temperature would be nearly

\section{$3^{\circ} \mathrm{C}$ higher in 3000 .}

When the authors accounted for the climate's sensitivity to the effects of increased atmospheric carbon, they found that only when the sensitivity is low could a more conservative mitigation rate of $1 \%$ per year implemented within the next 10 years meet the $2{ }^{\circ} \mathrm{C}$ target.

Nature Clim. Change http://

dx.doi.org/10.1038/

nclimate1302 (2011)

\section{CHEMISTR}

\section{Hydrogen made metallic}

It has long been predicted that hydrogen would become metallic when subjected to enough pressure, but researchers have been disappointed in the past when using pressures as high as 300 gigapascals at low temperatures. Mikhail Eremets and Ivan Troyan at the Max Planck Institute for Chemistry in Mainz, Germany, have produced opaque, conducting hydrogen by squeezing it with pressures greater than 220 gigapascals at room temperature.

At 260-270 gigapascals, the hydrogen became a reflective metal. The duo coated the diamond anvil cells used to pressurize the sample with thin layers of copper, gold or other materials to prevent hydrogen diffusing in and breaking the diamond. The study opens avenues of research into the structure of different phases of hydrogen. Nature Mater. http://dx.doi. org/10.1038/nmat3175 (2011)

AGRICULTURAL ECOLOGY

\section{Eco-farming fish with rice}

In southern China, farmers have been cultivating fish and rice in the same fields for more than 1,200 years with good reason, according to a group led by Xin Chen at Zhejiang University in Hangzhou, China. Farming fish and rice together achieves 